is in two parts. The first deals with the anatomy and physiology of the eyes of various animals. The domestic animals are dealt with in detail, and in addition reference is made to birds, fish and reptiles. The sections on animal vision and the optical system are compiled very well, and the author has correlated the work of others and contributed the results of his own observations.

The second part of the book is devoted to the clinical aspect and consists of two hundred pages. All aspects of veterinary ophthalmology are reviewed, and methods which have stood the test of time as well as new treatments are described. This section is introduced with a description of the clinical examina. tion of the eye followed by chapters dealing with anatomical regions of the eye. Clinicians and students will find this a valuable source to which to refer, especially with regard to the incidence, diagnosis and medical treatment of the conditions described so comprehensively. The surgical references are somewhat disappointing. No method of extirpation of the eyeball which might give promise of first intention healing is described. Many methods of dealing with entropion and ectropion are detailed and these defects, which are usually simple to treat, are made to appear complex. Extraction of the crystalline lens in the dog, on the other hand, seems simpler than most would agree. The book ends with fairly complete chapters on therapeutics and ophthalmic preparations in daily use.

It is hoped that the next edition might have the references removed from the text and placed at the end of each chapter. Some chapters, particularly that dealing with methods of examination, could be given titles of greater clarity.

Despite these few criticisms the wealth of information in this book, which is full of illustrations, line drawings, photomicrographs and photographs, should be studied by all who are interested in advan. cing their knowledge of veterinary ophthalmology. The author has filled a need, and the publishers should be congratulated on their part of the task.

C. Frost

\section{CHEMISTRY AND TECHNOLOGY OF WOOL-WAX}

\section{Wool Wax}

Chemistry and Technology. By Dr. E. Vernon Truter. Yp. xi +368. (London: Cleaver-Hume Press, Ltd., 1956.) 60s. net.

IN the preface to his book, Dr. Truter expresses the hope that this work - the first comprehensive and critical account of the chemistry and technology of wool-wax-will help to encourage further research and development on this most interesting subject. Undoubtedly the author has succeeded in presenting the subject in a most instructive manner and should, by virtue of this, provide a stimulating influence to prospective workers in his field. The diversity of subjects covered may be indicated by the fact that the topics discussed vary from the structure of the wool follicle to the stereochemistry of clathrate compounds and that there are 57I references.

The contents of the fleece and their distribution, and the factors affecting these variables are discussed fully in Chapter 1. Chapter 2 deals with the chemical constitution of the wax and describes the large amount of work that has been carried out on this subject in the past decade. The constitution and uses of suint, the water-soluble portion of wool-wax, merits a chapter on its own. There follows a critical discussion of the physical chemistry of oil-water emulsions which is aided by several photomicrographs and clearly drawn diagrams. The derivation and utilization of the principles involved in the recovery of wool-wax from oil-in-water and water-in-oil emulsions follow quite naturally, as does the account of the various saponification processes.

Of particular interest is the space devoted by the author to a discussion of the isolation, purification, determination and properties of cholesterol and isocholesterol. No fewer than 146 of the 356 pages are devoted to these topics. The chapter in which is described the preparation and uses of clathrate compounds ("Sorting Molecules by Size and Shape") is particularly interesting, albeit it suffers from a slight surfeit of thermodynamics. In the chapter entitled "Lanostane Derivatives" is given a comprehensive account of the step-wise elucidation of the structure of the one-time bete noire of the triterpene chemist, 'Ianosterol'. The account is presented logically and is helped in no small measure by a generous recourse to diagrammatic reaction schemes which are clear and unambiguous.

The chapter on steroidal derivatives begins with a short account of the stereochemistry of the steroid nucleus. This would have been better placed in the previous chapter on lanostane in order to explain the stereochemical notations used, for they are common to both classes of compounds. This chapter might be considered a valuable adjunct to the standard book of reference "Natural Products related to Phenanthrene" by Fieser and Fieser, since about half the references cited are later than 1949 the date of the last edition. After a very enlightening chapter which describes the remarkable 'Bradford Recovery Process' for the recovery of wool-wax from the city effluents, there are listed the many and varied uses of the wax in various states of purity. Space is also devoted to an account of the destructive distillation and vacuum distillation of wool-grease.

The book is written in a lucid and unassuming style, and is gratifyingly free from misprints; as a source of reference for workers on wool-wax and allied fields it should prove a valuable asset.

\section{A. LEWIS}

\section{MEASURE AND INTEGRAL}

Mass und Integral und ihre Algebraisierung

Von Prof. C. Carathéodory. Herausgegeben von P. Finsler, A. Rosenthal und R. Steuerwald. (Lehrbücher und Monographien aus dem Gebiete der Exakten Wissenschaften. Mathematische Reihe, Band 10.) Pp. 337. (Basel und Stuttgart: Birkhäuser Verlag, 1956.) 38.50 francs ; 38.50 D.M.

\section{$T$} HIS is a charming book; all mathematicians must regret that it is the last we shall have from its distinguished author. For some twenty years, in a series of papers, Carathéodory worked at the construction of a theory of measure which should start from the concept of a set of objects for which Boolean addition, multiplication and complementation could be defined, and should proceed from there to a measure theory and a definition of the integral, the Boolean ring playing a part analogous to that of the 